\title{
Microarray analysis of DNA damage repair gene expression profiles in cervical cancer cells radioresistant to ${ }^{252} \mathrm{Cf}$ neutron and X-rays
}

Yi Qing ${ }^{1 \dagger}$, Xue-Qin Yang ${ }^{1 \dagger}$, Zhao-Yang Zhong ${ }^{1}$, Xin Lei ${ }^{1}$, Jia-Yin Xie ${ }^{1}$, Meng-Xia Li', De-Bing Xiang ${ }^{2}$, Zeng-Peng Li', Zhen-Zhou Yang ${ }^{1}$, Ge Wang ${ }^{1}$, Dong Wang ${ }^{1 *}$

\begin{abstract}
Background: The aim of the study was to obtain stable radioresistant sub-lines from the human cervical cancer cell line HeLa by prolonged exposure to ${ }^{252} \mathrm{Cf}$ neutron and X-rays. Radioresistance mechanisms were investigated in the resulting cells using microarray analysis of DNA damage repair genes.

Methods: HeLa cells were treated with fractionated ${ }^{252} \mathrm{Cf}$ neutron and X-rays, with a cumulative dose of 75 Gy each, over 8 months, yielding the sub-lines HeLaNR and HeLaXR. Radioresistant characteristics were detected by clone formation assay, ultrastructural observations, cell doubling time, cell cycle distribution, and apoptosis assay. Gene expression patterns of the radioresistant sub-lines were studied through microarray analysis and verified by Western blotting and real-time PCR.

Results: The radioresistant sub-lines HeLaNR and HeLaXR were more radioresisitant to ${ }^{252} \mathrm{Cf}$ neutron and X-rays than parental HeLa cells by detecting their radioresistant characteristics, respectively. Compared to HeLa cells, the expression of 24 genes was significantly altered by at least 2-fold in HeLaNR cells. Of these, 19 genes were upregulated and 5 down-regulated. In HeLaXR cells, 41 genes were significantly altered by at least 2-fold; 38 genes were up-regulated and 3 down-regulated.

Conclusions: Chronic exposure of cells to ionizing radiation induces adaptive responses that enhance tolerance of ionizing radiation and allow investigations of cellular radioresistance mechanisms. The insights gained into the molecular mechanisms activated by these "radioresistance" genes will lead to new therapeutic targets for cervical cancer.
\end{abstract}

\section{Background}

Cervical cancer is a worldwide disease, with a high incidence and mortality [1] especially in developing countries. Approximately 500,000 cases of cervical cancer are diagnosed annually, with mortality around 40\% [2]. Radiotherapy is particularly effective for patients with cervical cancers at an advanced stage or that cannot be cured surgically. Low LET radiation (e.g., gamma rays, $\mathrm{X}$-rays) is generally used to treat cervical cancers, but its ability to cure local disease decreases with increasing tumor size, because the doses required to treat large

\footnotetext{
* Correspondence: dongwang64@hotmail.com

† Contributed equally

${ }^{1}$ Cancer Center, Daping Hospital and Research Institute of Surgery, Third Military Medical University, Chongqing, PR China
}

tumors exceed the toxicity limits of normal tissues [3]. High LET radiation such as neutron rays is associated with a low rate of repair of potentially lethal DNA damage, allowing better local control of the tumor and thus less chance of recurrence. Theoretically, high LET radiation has several advantages over low LET radiation: (a) more damage to hypoxic cells; (b) decreased repair of IR-induced damage; and (c) effectiveness at all stages of the cell cycle [4]. The 5-year overall survival rate of cervical cancer patients who received ${ }^{252} \mathrm{Cf}$ neutron ray radiotherapy was reported to be $76.8 \%$ at stage II and $70.9 \%$ at stage III [5]. Another study showed that the 10 -year survival rate was better in cervical cancer patients treated with ${ }^{252} \mathrm{Cf}$ neutron rays than in those treated with gamma radiation $(69.1 \%$ vs. $50.9 \%$,
C Biomed Central

(c) 2010 Qing et al; licensee BioMed Central Ltd. This is an Open Access article distributed under the terms of the Creative Commons Attribution License (http://creativecommons.org/licenses/by/2.0), which permits unrestricted use, distribution, and reproduction in any medium, provided the original work is properly cited. 
respectively) [6]. However, despite the improved efficacy of ${ }^{252} \mathrm{Cf}$ neutron rays in the therapy of cervical cancer, tumors recurrence has been reported.

A substantial body of evidence has implicated DNA as the primary target in lethal ionizing radiation (IR) [7]. In many human tumor lines, radiosensitivity correlated with DNA damage induction and repair [8-10]. The activity of the DNA damage repair pathway is one of the most important factors leading to radioresistance in tumors, including cervical cancer. This pathway as well as others contributing to radioresistance in cervical cancer can be studied by cDNA microarray analyses of gene expression. Thus, in the present work, long-term ${ }^{252} \mathrm{Cf}$ neutron ray and X-ray irradiation of HeLa cells was used to generate two radioresistant cell sub-lines, HeLaNR and HeLaXR, which provided a model system for studying the radioresistance mechanisms of cervical cancer cells. Insights into the mechanisms of resistance will contribute to improvements in cancer treatment.

\section{Methods \\ Cell lines}

The HeLa cell line was obtained from the American Type Culture Collection and cultured in DMEM-high glucose medium (GIBCO) supplemented with 10\% newborn calf serum (Biochrom AG), penicillin $(100 \mathrm{U} / \mathrm{ml})$, and streptomycin $(100 \mu \mathrm{g} / \mathrm{ml})$ (Sigma). Cells were incubated in $5 \%$ $\mathrm{CO}_{2}$ at $37^{\circ} \mathrm{C}$ and passaged 2-3 times weekly. ${ }^{252} \mathrm{Cf}$ neutron ray (HeLaNR) and X-ray (HeLaXR) resistant sublines were generated by continuous sublethal irradiation for 8 months with ${ }^{252} \mathrm{Cf}$ neutron and X-rays, respectively, with a total dose of 75 Gy each. The parental cell line (HeLa) and the radioresistant sub-lines (HeLaNR and HeLaXR) were maintained under the same conditions. To control for acute effects of IR, the radioresistant sublines were cultured for over 2 months after the last irradiation before being used in the analyses.

\section{Irradiation}

For X-ray treatment, cells were cultured in $25-\mathrm{cm}^{2}$ flasks until they reached $75 \%$ confluence and then irradiated at $200 \mathrm{cGy} / \mathrm{min}$, at room temperature, with a Precise linear accelerator (Elekta) operating at $8 \mathrm{MV}$. For ${ }^{252} \mathrm{Cf}$ neutron ray treatment, trypsinized cells were harvested in a tube and then irradiated with a neutron emission rate of $2.3 \times 10^{6} / \mathrm{s} / \mu \mathrm{g}$, a $\gamma$ emission rate of 1.3 $\times 10^{7} / \mathrm{s} / \mu \mathrm{g}$, and a dose rate in air of $23.4 \mathrm{mSv} / \mathrm{h} \cdot \mathrm{mg}$ at 1 $\mathrm{cm}$ from the source.

\section{Colony formation assay}

HeLa, HeLaNR, and HeLaXR cells were treated with 0, $2,4,6,8$, and $10 \mathrm{~Gy}$ of ${ }^{252} \mathrm{Cf}$ neutron or X-ray radiation. After 2 weeks, clones were fixed with methanol and stained with a $2 \%$ Giemsa solution (Merck) for $10 \mathrm{~min}$.
Stained clones that had more than 50 cells were counted and cloning efficiency calculated as: cloning efficiency $=$ (clone number/total cell number)*100\%. The cell survival fraction (SF) was determined. A cell survival curve was drafted using Microsoft Excel 2003 software and the single-hit multi-target model SF $=1-\left(1-\mathrm{e}^{-\mathrm{D} / \mathrm{D} 0}\right)^{\mathrm{N}}$, where SF is the survival fraction; $\mathrm{D}$, the radiation dose; $\mathrm{D}_{0}$, the mean death dose; and $\mathrm{N}$, the extrapolated number. $D_{q}$, the standard threshold dose, was determined from $\log \mathrm{N}=\mathrm{D}_{\mathrm{q}} / \mathrm{D}_{0}$; and $\mathrm{SF} 2$, the fraction surviving at 2 Gy, from the cell survival curve.

\section{Transmission electron microscopy (TEM)}

HeLa, HeLaNR, and HeLaXR cells were harvested in exponential growth phase and centrifuged at $1500 \mathrm{rpm}$ for $10 \mathrm{~min}$ at $4^{\circ} \mathrm{C}$. Cell pellets were fixed in a $2.5 \%$ glutaraldehyde solution. Fixed cells were washed twice with PBS, dehydrated three times sequentially in a graded series of acetone solutions, and then incubated overnight in a 1:1 volume ratio of $100 \%$ alcohol and embedding resin. Resin-embedded cells were placed in capsules and then transferred to a Pelco UV-2 Cryo Chamber, where they were polymerized with UV irradiation at $4^{\circ} \mathrm{C}$ for $48 \mathrm{~h}$. Ultrathin sections were prepared and then stained with uranyl acetate and lead citrate. Cellular uptake of nanoparticles was evaluated by TEM (TECNAI10, Philips).

\section{Cell doubling time}

HeLa, HeLaNR, and HeLaXR cells were trypsinized in exponential growth phase. Equal numbers of cells (about $1 \times 10^{4}$ ) were plated in 6-well culture plates (day 0 ) and cultured in $5 \% \mathrm{CO}_{2}$ at $37^{\circ} \mathrm{C}$. Viable cells were determined by the trypan blue exclusion test and counted in triplicate on days $1,2,3,4,5$, and 6 .

\section{Cell cycle analysis}

HeLa, HeLaNR, and HeLaXR cells were treated with 0 , 4 , and $16 \mathrm{~Gy}$ of ${ }^{252} \mathrm{Cf}$ neutron ray and X-ray radiation. At $24 \mathrm{~h}$ post-irradiation, the cells were harvested, fixed with $70 \%$ ethanol, and then stored at $4^{\circ} \mathrm{C}$. Cell cycle analysis was carried out by flow cytometry (FACSCalibur, Becton Dickinson) at $488 \mathrm{~nm}$.

\section{Apoptosis analysis}

HeLa, HeLaNR and HeLaXR cells were treated with 0, 4 and 16 Gy of ${ }^{252} \mathrm{Cf}$ neutron ray and X-ray radiation. At $48 \mathrm{~h}$ post-irradiation, the cells were harvested and then stained with annexin V-FITC and PI (Invitrogen). Cell apoptosis analysis was carried out by flow cytometry.

\section{RNA preparation and microarray analysis}

Total RNA was isolated from HeLa, HeLaNR, and HeLaXR cells with TRIzol $^{\circ}$ (Invitrogen) according to the 
manufacturer's instructions. SuperArray (Oligo GEArray Human DNA Damage Signaling Pathway Microarray) was used following the manufacturer's protocol to compare the gene expression profiles of the three cell lines, and the results interpreted with the GEArray Expression Analysis Suite. SuperArray contains 113 functionally well-characterized genes associated with the ATR/ATM signaling network, including transcriptional targets of DNA damage response (cell cycle arrest, apoptosis, and DNA repair). Controls consist of four normalizable genes (glyceraldehyde-3-phosphate dehydrogenase, beta-2-microglobulin, heat-shock protein 90$\alpha$, and $\beta$-actin) and a blank. The experiment was performed more than three times using different RNA preparations. The microarray data had been deposited in GEO database of NCBI. The Series number was GSE19526 http://www.ncbi.nlm.nih.gov/geo/query/acc. cgi?acc $=$ GSE19526 and the Platform number was GPL9811 http://www.ncbi.nlm.nih.gov/geo/query/acc. cgi?acc=GPL9811.

\section{Western blotting}

Total protein extracts were prepared from HeLa, HeLaNR, and HeLaXR cells. The proteins $(20 \mu \mathrm{g} / \mathrm{sam}-$ ple) were resolved by electrophoresis on $12 \%$ SDS-polyacrylamide gels, transferred to polyvinylidene difluoride membranes, and blocked in TBST $[50 \mathrm{mM}$ Tris- $\mathrm{HCl}$, $\mathrm{pH} 7.5,150 \mathrm{mM} \mathrm{NaCl}$ and $0.1 \%$ (v/v) Tween 20] containing $5 \%(\mathrm{w} / \mathrm{v})$ nonfat dry milk. The membrane was incubated with a 1:2000 dilution of GADD45 $\alpha$ (mouse monoclonal antibody, Abnova) and a 1:1000 dilution of BTG2 (goat polyclonal IgG, Santa Cruz) primary antibody overnight at $4^{\circ} \mathrm{C}$, washed three times in TBST, and then incubated with a 1:2000 dilution of horseradishperoxidase-labeled secondary antibody (Pierce) for 1 hour at $37^{\circ} \mathrm{C}$. The membrane was then reacted with chemiluminescent reagents (Pierce) and exposed onto film (Kodak). Bands intensities were analyzed using the Gel Doc 2000 apparatus and software (Quantity One, Bio-Rad). Protein loading was normalized with $\beta$-actin (Sigma).

\section{Real-time PCR}

Total RNA was isolated from HeLa, HeLaNR, and HeLaXR cells. Reverse transcription was performed with AMV reverse transcriptase (TaKaRa) and oligodT18 primers (TaKaRa). Real-time PCR was carried out using SYBR Green I (Molecular Probes) and the iQCycler thermocycler (Bio-Rad). Relative expression of the GADD45 $\alpha$ and BTG2 genes was measured by real-time quantitative RT-PCR using $\beta$-actin as internal control for possible contamination of genomic DNA and for normalization of variation in the amounts of PCR product loaded. Primer sequences were: 5'-AGTCAGCGCACGATCACTGTC-3' (forward) and 5'-GACGCGCAGGATGTTGATGTC-3' (reverse) for GADD45 $\alpha$, which generated a 183-bp fragment; 5'ACATGAGCCACGGGAAGGGAAC-3' (forward) and 5'-ATGCGAATGCAGCGGTAGCC-3' (reverse) for BTG2, which generated a 211-bp fragment. Real-time PCR was carried out as follows: initial denaturation for $5 \mathrm{~min}$ at $94^{\circ} \mathrm{C}$ and $42 \mathrm{PCR}$ cycles consisting of $15 \mathrm{~s}$ at $94^{\circ} \mathrm{C}, 15 \mathrm{~s}$ at $58^{\circ} \mathrm{C}$, and $18 \mathrm{~s}$ at $72^{\circ} \mathrm{C}$. Standards and cDNA samples were amplified in triplicate in the same reaction plate in at least three independent experiments.

\section{Statistical analysis}

Quantitative data were obtained from three independent experiments and expressed as mean \pm SD. Statistical difference between two groups was determined using Student's $t$ test. $P$ values were-two sided; $P<0.05$ was considered as statistically significant.

\section{Results}

\section{Radiosensitivity}

Radiation-survival curves, generated according to the above-described methods, were derived from colony formation assays of the three cell lines after different doses of ${ }^{252} \mathrm{Cf}$ neutron and X-rays (Figure 1 ). These curves were then used to determine $D_{0}, D_{q}$, and SF2 (Table 1). Under equal doses of ${ }^{252} \mathrm{Cf}$ neutron ray and X-ray irradiation, the $D_{0}, D_{q}$, and SF2 values of the HeLaNR and HeLaXR cells were higher than those of the HeLa cells, indicating that the sub-lines were more radioresistant than the parent cells.

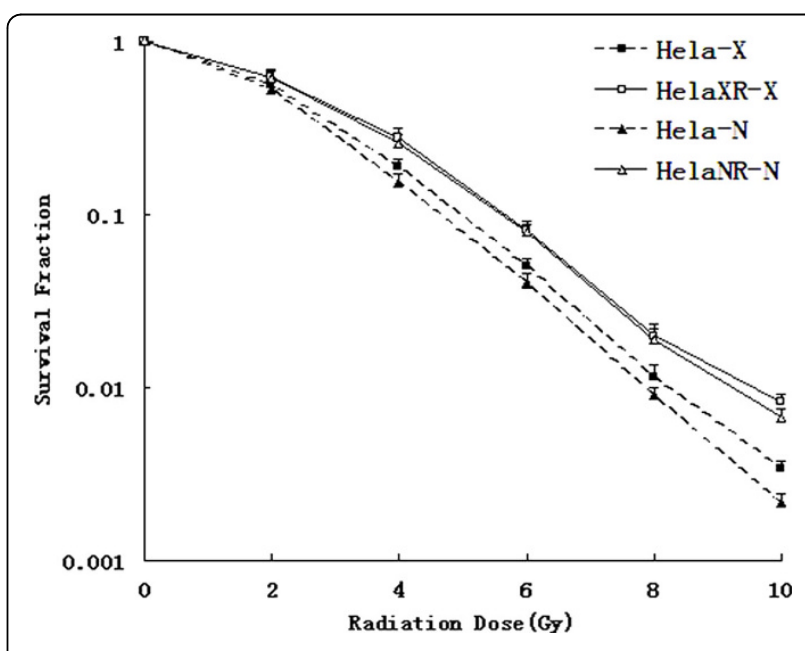

Figure 1 Survival fraction curves of HeLa, HeLaNR and HeLaXR cells. The radiation survival fraction curve derived from colony formation assays of HeLa, HeLaNR, and HeLaXR cells after different doses of ${ }^{252} \mathrm{Cf}$ neutron rays and $\mathrm{X}$-rays. HeLaNR and HeLaXR cells are more radioresistant to IR than parental cells. 
Table $1 D_{0}, D_{q}$, and SF2 values in HeLa, HeLaNR, and HeLaXR cells

\begin{tabular}{cccc}
\hline Group & $\mathbf{D}_{\mathbf{0}}(\mathbf{G y})$ & $\mathbf{D}_{\mathbf{q}}$ (Gy) & $\mathbf{S F}_{\mathbf{2}}$ \\
\hline HeLa-N & 1.45 & 0.59 & 0.52 \\
HeLaNR-N & 1.84 & 0.67 & 0.61 \\
HeLa-X & 1.58 & 0.61 & 0.55 \\
HeLaXR-X & 1.88 & 0.7 & 0.63 \\
\hline
\end{tabular}

\section{Ultrastructure}

The ultrastructure of HeLa, HeLaNR, and HeLaXR cells was examined by TEM (Figure 2). In HeLa cells, microvilli were present on the surface and the cytoplasm contained abundant mitochondria and ribosomes. In the radioresistant sub-lines, swelling of mitochondria, vacuolization, dilatation of the endoplasmic reticulum, and myelin figures were observed. Thus, in the HeLaNR and HeLaXR sub-lines, the ultrastructural changes induced by long-term irradiation persisted even $>2$ months after the last radiation treatment.

\section{Cell proliferation}

Cell doubling time, $t_{\mathrm{d}}$, was estimated by the following formula:

$$
t_{\mathrm{d}}=\ln 2 *\left(t_{2}-t_{1}\right) / \ln \left(X_{2} / X_{1}\right)
$$

where $X_{1}$ and $X_{2}$ are the number of cultured cells at the current $\left(t_{2}\right)$ and previous $\left(t_{1}\right)$ measurements. As shown in Figure 3 , the cell doubling times of the HeLaNR and HeLaXR cells $(33.12 \pm 3.67 \mathrm{~h}$, and $36.94 \pm$ $3.16 \mathrm{~h}$, respectively) were longer than those of the parent HeLa cells $(28.62 \pm 2.77 \mathrm{~h})$.

\section{Cell cycle distribution}

The cell cycle distribution of HeLa, HeLaNR, and HeLaXR cells $24 \mathrm{~h}$ after ${ }^{252} \mathrm{Cf}$ neutron ray and X-ray irradiation was determined by flow cytometry (Figure 4). In HeLa cells, exposure to a radiation dose of 4 Gy significantly increased the proportion of cells in G2 and decreased the proportion of cells in G1. The proportion of G2-arrested

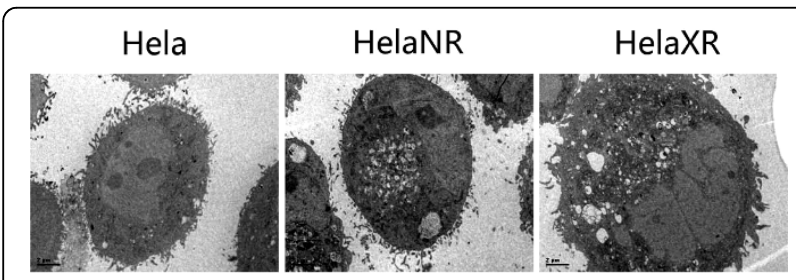

Figure 2 Ultrastructural features of HeLa, HeLaNR, and HeLaXR cells examined by TEM $(\times 3,700)$. Microvilli are present on the HeLa cell surface and the cytoplasm contains abundant mitochondria and ribosome. In the radioresistant sub-lines, mitochondrial swelling, vacuolization, dilatation of the endoplasmic reticulum, and myelin figures are seen.

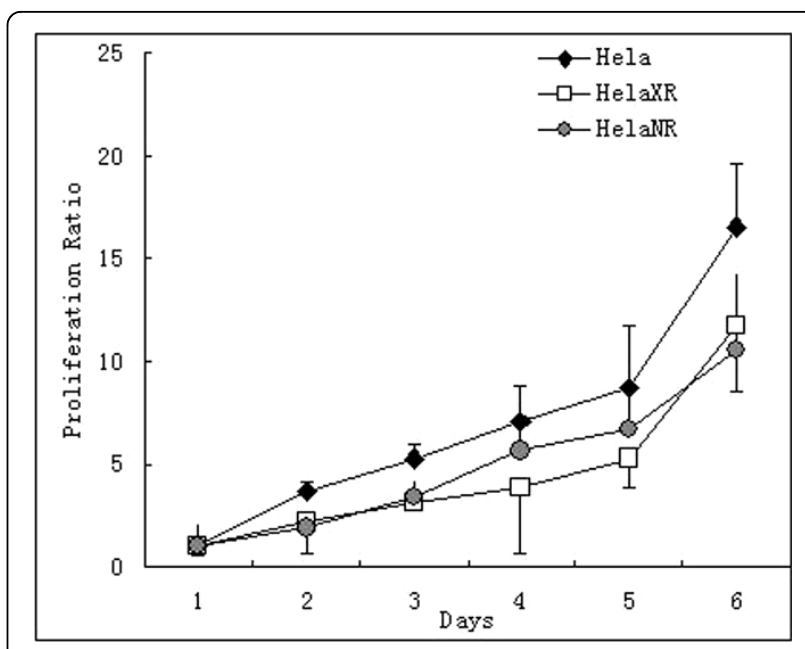

Figure 3 Cell growth curves of HeLa, HeLaNR and HeLaXR cells. The cell doubling time of HeLaNR and HeLaXR cells is $33.12 \pm 3.67 \mathrm{~h}$ and $36.94 \pm 3.16 \mathrm{~h}$, respectively, is longer than that of the parent HeLa cells $(28.62 \pm 2.77 \mathrm{~h})$.

HeLa cells was even greater following 16-Gy irradiation. In the HeLaNR and HeLaXR sub-lines, however, the proportion of cells in G2 did not increase after irradiation with $4 \mathrm{~Gy}$. At $16 \mathrm{~Gy}$, cells of both sub-lines became arrested in G2 but the proportion was much lower than in HeLa cells. Thus, cells of the radioresistant sub-lines probably arrested in the G1 phase of the cell cycle.

\section{Cell apoptosis}

The level of apoptosis was analyzed by flow cytometry $48 \mathrm{~h}$ after 0,4 , and $16 \mathrm{~Gy}{ }^{252} \mathrm{Cf}$ neutron ray and $\mathrm{X}$-ray irradiation (Figure 5). At $0 \mathrm{~Gy}$, the apoptosis rate was $0.93-2.71 \%$ for all three cell lines. At 4 and $16 \mathrm{~Gy}$, the apoptosis rate of HeLa cells was much higher than that of the radioresisitant sub-lines (4 Gy: 9.32 vs 3.84, 7.94 vs 5.43; 16 Gy: 22.47 vs 7.28, 20.03 vs 11.1, $p<0.05)$. Thus, the sub-lines HeLaXR and HeLaNR were more radioresistant than the parental HeLa cell line.

\section{Gene expression}

Using stringent criteria for array analysis ( $\geq 2$-fold change in expression), we identified 113 genes related to DNA damage signaling pathways that were differentially expressed in the parental HeLa cells compared to radioresistant HeLaXR and HeLaNR cells (Table 2). Of the 24 genes significantly altered by at least 2-fold in HeLaNR cells, 19 were up-regulated and 5 down-regulated. Likewise, of the 41 genes significantly altered by at least 2 -fold in HeLaXR cells, 38 were up-regulated and 3 down-regulated. For the two radioresistant sub-lines, the similar overall trend in gene-expression changes indicated that long-term exposure to ${ }^{252} \mathrm{Cf}$ neutron and Xrays had resulted in a similar induction of genes involved 


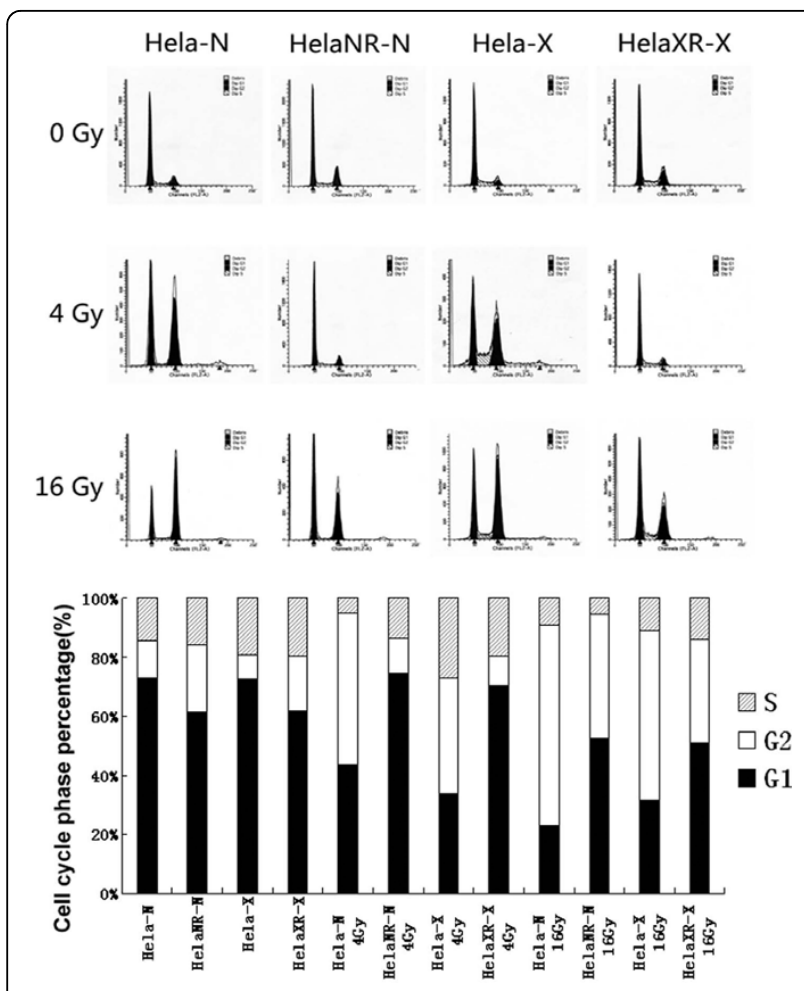

Figure 4 Cell cycle distribution in the parent HeLa cells and the two radioresistant sub-lines $\mathbf{2 4} \mathrm{h}$ after irradiation. Exposure of HeLa cells to a radiation dose of 4 Gy significantly increased the proportion of cells in the $\mathrm{G} 2$ phase of the cell cycle and decreased the proportion of cells in G1. The degree of G2 arrest was more apparent after irradiation with $16 \mathrm{~Gy}$. The cell cycle distribution pattern of the radioresistant sub-lines also changed but without an increase in G2 cells after irradiation with $4 \mathrm{~Gy}$. Increasing the irradiation doses to $16 \mathrm{~Gy}$ induced $\mathrm{G} 2$ arrest but the proportion of arrested cells was much lower than in the HeLa cell population.

in DNA damage signaling pathways. But genes encoding homologous recombination, nonhomologous end-joining, mismatch repair, and cell cycle arrest functions were more highly expressed in cells resistant to X-rays than in cells resistant to ${ }^{252} \mathrm{Cf}$ neutron rays.

\section{Western blotting and real-time PCR}

Changes in gene expression detected in the microarrays were validated by Western blotting and real-time PCR. Based on the results shown in Figure 6, two genes, BTG2 and GADD45 $\alpha$, were chosen for further analysis and validation of the microarray data by Western blotting and real-time PCR. As shown by Western blotting, BTG2 protein expression was up-regulated in the resistant sub-lines, especially in HeLaNR cells, while the expression of GADD $45 \alpha$ protein was down-regulated in both resistant sub-lines. PCR analysis showed that BTG2 and GADD45 $\alpha$ mRNA expression paralleled that of the respective proteins.

\section{Discussion}

Chronic exposure of cells to IR induced an adaptive response that resulted in enhanced tolerance to the subsequent cytotoxicity of IR [11-13]. In this study, HeLa cells were irradiated with fractionated ${ }^{252} \mathrm{Cf}$ neutron and $\mathrm{X}$-rays, yielding two radioresistant cell sub-lines. The mechanisms of this increased cellular radioresistance were investigated by comparing changes in the gene expression profiles of the parent HeLa cells with those of the HeLaNR and HeLaXR sub-lines.

Post-irradiation survival of the radioresistant sub-lines was significantly higher than that of the parental cells, with increased $D_{0}$ and $D_{q}$. This resistant phenotype appears to be stable because it did not change after continuous culture of the sub-lines for $>2$ months in the absence of further irradiation. Similar findings were reported in the radioresistant human fibrosarcoma cell line HT1080R, obtained by long-term exposure to X-rays [14]. In Escherichia coli, radioresistant mutant bacterial strains were produced by daily X-ray irradiation [15]. Radiation resistance after long-term fractionated radiation has also been reported for breast [16], pancreatic [17], esophageal [18], and nasopharyngeal [19] cancer cells.

Tumor cells are heterogeneous with respect to their radioresponsiveness. The radioresistant phenotype is ascribed to several factors, including alterations in cell cycle checkpoints, slowed growth, and decreased apoptosis [20]. Here, the ultrastructure, proliferation, cell cycle distribution, and apoptosis rate of the radioresistant sub-lines were studied. As shown by TEM, HeLaNR and HeLaXR cells were ultrastructurally altered after long-term exposure to IR, even after $>2$ months of culture after the last radiation dose. The cell doubling times of these sub-lines were longer than that of HeLa cells, consistent with the results of Russell et al. [11].

The cell cycle distribution pattern is strongly disturbed by irradiation; in turn, radiosensitivity depends on cell cycle position and cell cycle progression [21]. In a previous study, radiosensitive AT cells were shown to lack G1 arrest, accumulating instead at G2, while the G2 phase of radioresistant REC-derived cells was significantly prolonged [22]. We found that HeLaNR, HeLaXR, and HeLa cells differed in their cell cycle distribution, with HeLaNR and HeLaXR sub-lines most likely arrested in G1. This difference between the parent and the two sub-lines may reflect their different radiosensitivities. Likewise, IR-induced apoptosis was found to be better tolerated by the radioresistant HeLaNR and HeLaXR cells than by the parental HeLa cells. Previous studies provided evidence of the important role played by apoptosis in radiation-induced cell death and as a determinant of radiosensitivity $[23,24]$. 


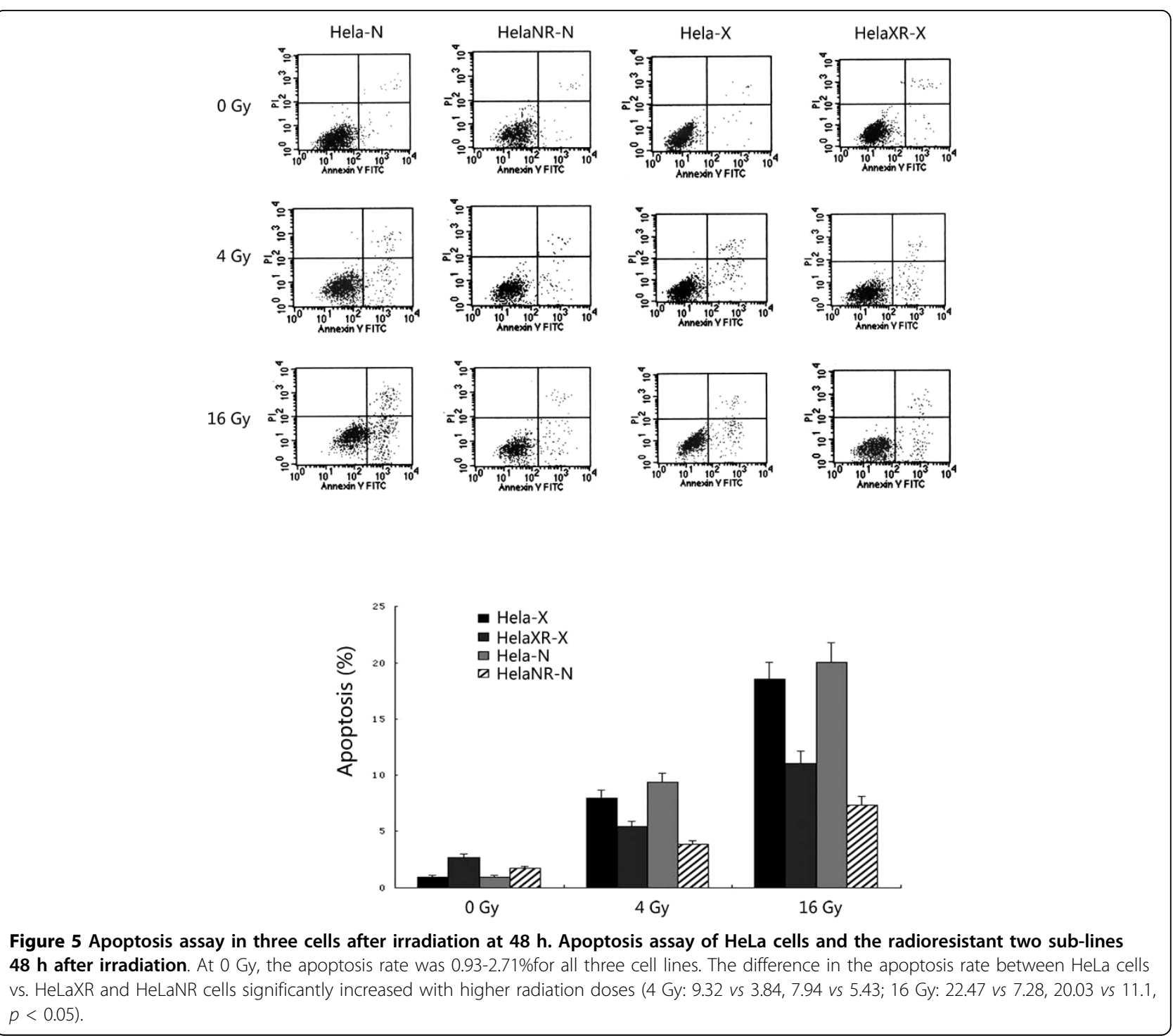

DNA microarray technology is a powerful technique to detect the biological response of thousands of genes to external stimuli, including IR [25]. Gene expression profiling by DNA microarray has been applied to classify disease stages and predict treatment response to radiotherapy in cervical cancer [26-31]. In these previous studies, sets of genes associated with pathways such as apoptosis (e.g., bax, bcl-2), DNA damage repair (e.g., Ku80, GADD45, XRCC5), cell adhesion (e.g., ICAM-3), angiogenesis (e.g., HIF-1a), and tumor cell invasion (e.g., CTSL, CTSB) were identified.

Here, microarray analysis was used to identify the gene expression patterns of two radioresistant sub-lines derived from HeLa cells. Although many stress-responsive genes are inducible by IR [32], we found that the expression of only a small fraction of the radiation-inducible genes, such as those involved in cell cycle checkpoints, apoptosis, and DNA repair [33], was altered in our radioresistant sub-lines. For the two radioresistant sub-lines, the similar overall trend in gene-expression changes indicated that long-term exposure to ${ }^{252} \mathrm{Cf}$ neutron and X-rays had resulted in a similar induction of genes involved in DNA damage signaling pathways. The number of genes that are involved in homologous recombination and nonhomologous end-joining, processes that result in altered gene expression, was higher in HeLaXR cells ( 8 and 3, respectively) than in HeLaNR cells ( 2 and 1, respectively). Furthermore, the number of cell cycle arrest and mismatch repair genes expressed was higher in HeLaXR cells ( 7 and 3 , respectively) than in HeLaNR cells (3 and 1 , respectively) whereas the number of base excision repair genes expressed in the two sub-lines was almost the same (4 in HeLaXR cells and 5 in HeLaNR 
Table 2 Gene expression changes in HeLaNR and HeLaXR cell lines ( $\geq 2$-fold)

\begin{tabular}{|c|c|c|c|c|}
\hline \multirow[t]{2}{*}{ GeneBank } & \multirow[t]{2}{*}{ Symbol } & \multirow[t]{2}{*}{ Gene Function } & \multicolumn{2}{|c|}{ Regulation Mode } \\
\hline & & & HeLaNR* & HeLaXR* \\
\hline NM_000051 & ATM & Other genes involved in DNA repair & & up \\
\hline NM_006763 & BTG2 & Other genes involved in DNA repair & up & \\
\hline NM_001279 & CIDEA & Apoptosis genes & up & up \\
\hline NM_014430 & CIDEB & Apoptosis genes & up & up \\
\hline NM_000082 & CKN1 & Nucleotide excision repair & up & \\
\hline NM_001923 & DDB1 & Nucleotide excision repair & up & up \\
\hline NM_007068 & $\mathrm{DMC} 1$ & Nucleotide excision repair & & up \\
\hline NM_005236 & ERCC4 & Nucleotide excision repair & up & \\
\hline NM_006705 & GADD45G & Apoptosis genes & up & \\
\hline NM_001515 & GTF2H2 & Nucleotide excision repair & up & \\
\hline NM_016426 & GTSE1 & Cell cycle arrest & & up \\
\hline NM_004507 & HUS1 & Cell cycle arrest & & up \\
\hline NM_054111 & IHPK3 & Apoptosis genes & up & \\
\hline NM_001567 & INPPL1 & Other genes involved in DNA repair & up & up \\
\hline NM_033276 & KUB3 & Nonhomologous end-joining & up & up \\
\hline NM_000234 & LIG1 & Nucleotide excision repair & & up \\
\hline NM_002758 & MAP2K6 & Cell cycle arrest & & up \\
\hline NM_002969 & MAPK12 & Cell cycle arrest & up & up \\
\hline NM_005590 & MRE11A & Homologous recombination & & up \\
\hline NM_018177 & N4BP2 & Other genes involved in DNA repair & & up \\
\hline NM_002528 & NTHL1 & Base excision repair & up & up \\
\hline NM_020418 & PCBP4 & Apoptosis genes & & up \\
\hline D38500 & PMS2L4 & Mismatch repair & & up \\
\hline NM_005395 & PMS2L9 & Mismatch repair & & up \\
\hline NM_007254 & PNKP & Base excision repair & up & up \\
\hline NM_014330 & PPP1R15A & Apoptosis genes & & up \\
\hline NM_006904 & PRKDC & Nonhomologous end-joining & & up \\
\hline NM_002873 & RAD17 & Cell cycle arrest & & up \\
\hline NM_006265 & RAD21 & Apoptosis genes & up & \\
\hline NM_005053 & RAD23A & Nucleotide excision repair & & up \\
\hline NM_002875 & RAD51 & Homologous recombination & & up \\
\hline NM_133509 & RAD51L1 & Homologous recombination & & up \\
\hline NM_002878 & RAD51L3 & Homologous recombination & & up \\
\hline NM_002879 & RAD52 & Homologous recombination & up & up \\
\hline NM_003579 & RAD54L & Homologous recombination & & up \\
\hline NM_004584 & RAD9A & Cell cycle arrest & & up \\
\hline NM_016316 & REV1L & Other genes involved in DNA repair & & up \\
\hline NM_000546 & TP53 & Apoptosis genes & & up \\
\hline NM_016381 & TREX1 & Mismatch repair & & up \\
\hline NM_007205 & TREX2 & Other genes involved in DNA repair & & up \\
\hline NM_003362 & UNG & Base excision repair & up & up \\
\hline NM_021147 & UNG2 & Base excision repair & up & up \\
\hline NM_005431 & $\mathrm{XRCC2}$ & Homologous recombination & & up \\
\hline NM_005432 & XRCC3 & Homologous recombination & up & up \\
\hline NM_003401 & $\mathrm{XRCC} 4$ & Nonhomologous end-joining & & up \\
\hline NM_001239 & $\mathrm{CCNH}$ & Nucleotide excision repair & & down \\
\hline NM_004083 & DDIT3 & Cell cycle arrest & down & down \\
\hline NM_001924 & GADD45A & Apoptosis genes & down & down \\
\hline NM_002311 & LIG3 & Base excision repair & down & \\
\hline NM_000534 & PMS1 & Mismatch repair & down & \\
\hline NM_002873 & RAD17 & Cell cycle arrest & down & \\
\hline
\end{tabular}




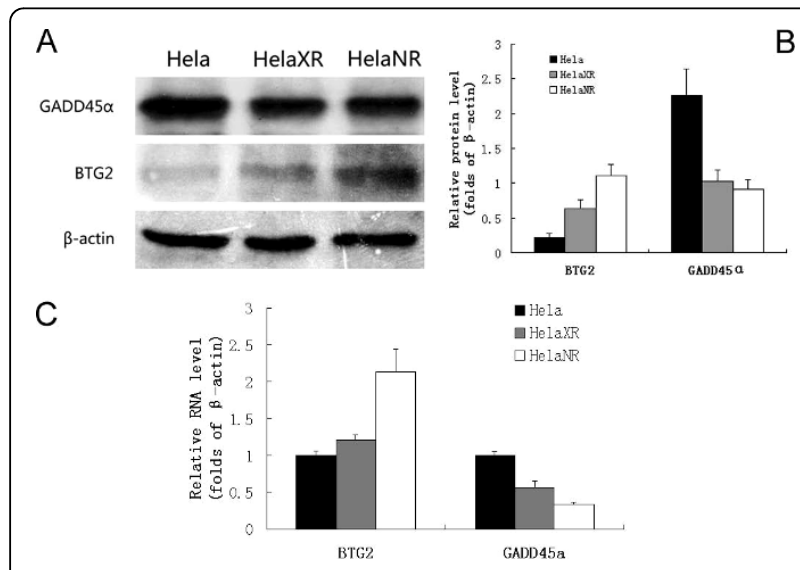

Figure 6 BTG2 and GADD45 $\alpha$ protein and mRNA expression in HeLa, HeLaNR and HeLaXR cells. BTG2 protein expression is upregulated in the sub-lines, especially HeLaNR. GADD45 $\alpha$ protein expression is down-regulated in the sub-lines (A and B). Changes in BTG2 and GADD45 $\alpha$ mRNA expression paralleled those in the protein levels (C).

cells). Hence, our results indicated that the expression of genes encoding homologous recombination, nonhomologous end-joining, mismatch repair, and cell cycle arrest functions was more closely related to X-ray radioresistance than to ${ }^{252} \mathrm{Cf}$ neutron ray radioresistance.

BTG2 and GADD45 $\alpha$ mRNA and protein expression levels were determined by real-time PCR and Western blot and the results confirmed the microarray data. BTG2 is an antiproliferative gene and one of the early growth response genes [34]. In a previous study, we investigated the expression of BTG2 and its role in hepatic cancer [35]. BTG2 overexpression inhibits G1-S progression through transcriptional regulation of cyclin D1 in the presence of pRB [36]. In NIH3T3 cells, forced expression of BTG2 provoked a marked inhibition of cell proliferation [34]. BTG2 was also identified as a differentiation and anti-apoptotic factor in neurogenesis [37]. In the present study, BTG2 mRNA and protein were found to be overexpressed in the two radioresistant sub-lines, suggesting that BTG2 plays an important role in resistance to IR-induced apoptosis and G1 arrest.

GADD45 $\alpha$ is a downstream target of p53 and a member of a group of genes induced by DNA damaging agents and growth arrest signals. KLOPP et al [38] examined 12 cervical cancer patients with microarray and find that GADD $45 \alpha$ is upregulated by radiation in NED (no evidence of disease) patients (1.13) and downregulated $(0.96)$ in recurrent-disease patients $(\mathrm{p}=0.36)$. Moreover, we find that the expression of GADD45 $\alpha$ is downregulated in radioresitant sublines HeLaNR and HeLaXR. GADD45 $\alpha$ is thought to be involved in cell cycle control at the G2-M checkpoint [39] and in the induction of cell death $[40,41]$ following DNA damage. It may interact with MEKK4/MTK1 [40] and activates the JNK/p38 [41] signaling pathway, which induces apoptosis. Thus, low-level expression of GADD45 $\alpha$ may in part explain the radioresistance of HeLaNR and HeLaXR cells to IR-induced apoptosis.

\section{Conclusions}

In the present study, radioresistance mechanisms in cells chronically exposed to IR were investigated using DNA microarray analysis. Comprehensive expression profiles of genes involved in DNA damage signaling pathway were generated in HeLa and two radioresistant sub-lines in order to identify those genes whose expression correlated with radioresistance. Further investigations of these and other "radioresistance" genes will provide new insights in our understanding of the molecular mechanisms of radioresistance, potentially leading to new therapeutic targets for cervical cancer.

\section{Acknowledgements}

We thank Dr. Ping Li, Dr. Nan Dai, Dr. Xiao-Jing Cao, Dr. Shu-Liang Yu, Miss Yu-Xin Yang, Miss Ling Liao, and Mr. Lin-Li Zeng for their kind and excellent technical assistance.

Financial Support: National Natural Science Foundation of China (no. 30472004), Natural Science Foundation of Chongqing (no. 2004BB5246) to Prof. Dong Wang and Research Foundation of Third Military Medical University (no. 2007XG36) to Dr. Xue-Qin Yang.

\section{Author details}

${ }^{1}$ Cancer Center, Daping Hospital and Research Institute of Surgery, Third Military Medical University, Chongqing, PR China. 'Department of Pathology, Daping Hospital and Research Institute of Surgery, Third Military Medical University, Chongqing, PR China.

\section{Authors' contributions}

$Y Q$ carried out most of the experimental work and contributed to draft the manuscript. $X L$ and JYX contributed to the present work by accomplishing cell culture treatments and radiation of cell lines. MXL and DBX contributed to performed western blot and real-time PCR. ZYZ and ZZY performed cell cycle analysis and cell apoptosis. ZPL carried out TEM analysis. XQY contributed to microarray analysis. GW contributed to elaboration of data. DW participated and coordinated the study, compiled and finalized the manuscript. All authors read and approved the final manuscript.

\section{Competing interests}

The authors declare that they have no competing interests.

Received: 1 May 2009

Accepted: 25 February 2010 Published: 25 February 2010

\section{References}

1. Pontén J, Adami HO, Bergström R, Dillner J, Friberg LG, Gustafsson $L$, Miller AB, Parkin DM, Sparén P, Trichopoulos D: Strategies for global control of cervical cancer. Int J Cancer 1995, 60:1-26.

2. Harima Y, Togashi A, Horikoshi K, Imamura M, Sougawa M, Sawada S, Tsunoda T, Nakamura Y, Katagiri T: Prediction of outcome of advanced cervical cancer to thermoradiotherapy according to expression profiles of 35 genes selected by cDNA microarray analysis. Int I Radiat Oncol Biol Phys 2004, 60:237-248.

3. Ma BB, Bristow RG, Kim J, Siu LL: Combined-modality treatment of solid tumors using radiotherapy and molecular targeted agents. J Clin Oncol 2003, 21:2760-2776. 
4. Withers HR: Biological basis for high-LET radiotherapy. Radiology 1973, 108:131-137.

5. Marjina LA, Kiseleva MV, Chekhonadsky VN: Radiation treatment of the cervix uteri cancer with usage of high activity ${ }^{252} \mathrm{Cf}$ sources. Radiother Oncol 2002, 63(Suppl):s21.

6. Tacev T, Ptácková B, Strnad V: Californium-252 $\left({ }^{252} \mathrm{Cf}\right)$ versus conventional gamma radiation in the brachytherapy of advanced cervical carcinoma long-term treatment results of a randomized study. Strahlenther Onkol 2003, 179:377-384

7. Elkind MM: DNA damage and cell killing. Cause and effect?. Cancer 1985, 56:2351-2363.

8. Thompson LH, Brookman KW, Dillehay LE, Carrano AV, Mazrimas JA, Mooney $\mathrm{CL}$, Minkler $\mathrm{JL}$ : A CHO-cell strain having hypersensitivity to mutagens, a defect in DNA strand-break repair, and an extraordinary baseline frequency of sister-chromatid exchange. Mutat Res 1982, 95:427-440.

9. Kelland $L R$, Edwards $S M$, Steel GG: Induction and rejoining of DNA double-strand breaks in human cervix carcinoma cell lines of differing radiosensitivity. Radiat Res 1988, 116:526-538.

10. Schwartz JL, Rotmensch J, Giovanazzi S, Cohen MB, Weichselbaum RR: Faster repair of DNA double-strand breaks in radioresistant human tumor cells. Int J Radiat Oncol Biol Phys 1988, 15:907-912.

11. Russell J, Wheldon TE, Stanton P: A radioresistant variant derived from a human neuroblastoma cell line is less prone to radiation-induced apoptosis. Cancer Res 1995, 55:4915-4921.

12. Dahlberg WK, Azzam El, Yu Y, Little JB: Response of human tumor cells of varying radiosensitivity and radiocurability to fractionated irradiation. Cancer Res 1999, 59:5365-69.

13. Pearce AG, Segura TM, Rintala AC, Rintala-Maki ND, Lee H: The generation and characterization of a radiation-resistant model system to study radioresistance in human breast cancer cells. Radiat Res 2001, 156:739-750.

14. Wei $K$, Kodym R, Jin C: Radioresistant cell strain of human fibrosarcoma cells obtained after long-term exposure to x-rays. Radiat Environ Biophys 1998, 37:133-137.

15. Ewing D: Production of radiation-resistant E. coli strains by daily $X$ irradiation. Int J Radiat Biol 1997, 71:253-258.

16. Wazer $D E$, Joyce $M$, Jung $L$, Band $V$ : Alterations in growth phenotype and radiosensitivity after fractionated irradiation of breast carcinoma cells from a single patient. Int J Radiat Oncol Biol Phys 1993, 26:81-88.

17. Ogawa K, Utsunomiya T, Mimori K, Tanaka F, Haraguchi N, Inoue H, Murayama S, Mori M: Differential gene expression profiles of radioresistant pancreatic cancer cell lines established by fractionated irradiation. Int J Oncol 2006, 28:705-713.

18. Fukuda K, Sakakura C, Miyagawa K, Kuriu Y, Kin S, Nakase Y, Hagiwara A, Mitsufuji S, Okazaki Y, Hayashizaki Y, Yamagishi H: Differential gene expression profiles of radioresistant oesophageal cancer cell lines established by continuous fractionated irradiation. Br J Cancer 2004 91:1543-1550

19. Chang JT, Chan SH, Lin CY, Lin TY, Wang HM, Liao CT, Wang TH, Lee LY, Cheng AJ: Differentially expressed genes in radioresistant nasopharyngeal cancer cells: gp96 and GDF15. Mol Cancer Ther 2007, 6:2271-2279

20. Maity A, Kao GD, Muschel RJ, McKenna WG: Potential molecular targets for manipulating the radiation response. Int I Radiat Oncol Biol Phys 1997, 37:639-53.

21. Pawlik TM, Keyomarsi K: Role of cell cycle in mediating sensitivity to radiotherapy. Int J Radiat Oncol Biol Phys 2004, 59:928-942.

22. Iliakis G, Metzger L, Muschel RJ, McKenna WG: Induction and repair of DNA double strand breaks in radiation-resistant cells obtained by transformation of primary rat embryo cells with the oncogenes $\mathrm{H}$-ras and v-myc. Cancer Res 1990, 50:6575-6579.

23. Verheij M, Bartelink H: Radiation-induced apoptosis. Cell Tissue Res 2000, 301:133-142

24. Meyn RE, Stephens LC, Milas L: Programmed cell death and radioresistance. Cancer Metastasis Rev 1996, 15:119-131.

25. Bentzen SM: Preventing or reducing late side effects of radiation therapy: radiobiology meets molecular pathology. Nat Rev Cancer 2006, 6:702-713

26. Kitahara O, Katagiri T, Tsunoda T, Harima Y, Nakamura Y: Classification of sensitivity or resistance of cervical cancers to ionizing radiation according to expression profiles of 62 genes selected by cDNA microarray analysis. Neoplasia 2002, 4:295-303.

27. Wong YF, Selvanayagam ZE, Wei N, Porter J, Vittal R, Hu R, Lin Y, Liao J, Shih JW, Cheung TH, Lo KW, Yim SF, Yip SK, Ngong DT, Siu N, Chan LK, Chan CS, Kong T, Kutlina E, McKinnon RD, Denhardt DT, Chin KV, Chung TK: Expression genomics of cervical cancer: molecular classification and prediction of radiotherapy response by DNA microarray. Clin Cancer Res 2003, 9:5486-5492.

28. Harima Y, Togashi A, Horikoshi K, Imamura M, Sougawa M, Sawada S, Tsunoda T, Nakamura Y, Katagiri T: Prediction of outcome of advanced cervical cancer to thermoradiotherapy according to expression profiles of 35 genes selected by CDNA microarray analysis. Int I Radiat Oncol Biol Phys 2004, 60:237-248.

29. Chung YM, Kim BG, Park CS, Huh SJ, Kim J, Park JK, Cho SM, Kim BS, Kim JS, Yoo YD, Bae DS: Increased expression of ICAM-3 is associated with radiation resistance in cervical cancer. Int J Cancer 2005, 117:194-201.

30. Wong YF, Sahota DS, Cheung TH, Lo KW, Yim SF, Chung TK, Chang AM, Smith DI: Gene expression pattern associated with radiotherapy sensitivity in cervical cancer. Cancer J 2006, 12:189-193.

31. Harima Y, Sawada S, Miyazaki Y, Kin K, Ishihara H, Imamura M, Sougawa M, Shikata N, Ohnishi T: Expression of Ku80 in cervical cancer correlates with response to radiotherapy and survival. Am J Clin Oncol 2003, 26:e80-85.

32. Fornace AJ Jr, Amundson SA, Bittner M, Myers TG, Meltzer P, Weinsten JN, Trent J: The complexity of radiation stress responses: analysis by informatics and functional genomics approaches. Gene Expr 1999, 7:387-400

33. Maity A, McKenna WG, Muschel RJ: The molecular basis for cell cycle delays following ionizing radiation: a review. Radiother Oncol 1994, 31:1-13.

34. Rouault JP, Falette N, Guéhenneux F, Guillot $C$, Rimokh R, Wang Q, Berthet C, Moyret-Lalle C, Savatier P, Pain B, Shaw P, Berger R, Samarut J, Magaud JP, Ozturk M, Samarut C, Puisieux A: Identification of BTG2, an antiproliferative p53-dependent component of the DNA damage cellular response pathway. Nat Genet 1996, 14:482-486.

35. Wang G, Zhang XR, Hu L, Wang J, Leng ER, Fang DC, Yang XM, Zhang Y, He FC: Rapid induction of mRNAs for liver regeneration genes by hepatopoietin and partial hepatectomy. Zhonghua Gan Zang Bing Za Zhi 2002, 10:256-259.

36. Guardavaccaro D, Corrente G, Covone F, Micheli L, D'Agnano I, Starace G, Caruso M, Tirone F: Arrest of G(1)-S progression by the p53-inducible gene PC3 is Rb dependent and relies on the inhibition of cyclin D1 transcription. Mol Cell Biol 2000, 20:1797-1815.

37. el-Ghissassi F, Valsesia-Wittmann S, Falette N, Duriez C, Walden PD, Puisieux A: BTG2(TIS21/PC3) induces neuronal differentiation and prevents apoptosis of terminally differentiated PC12 cells. Oncogene 2002, 21:6772-6778.

38. Klopp AH, Jhingran A, Ramdas L, Story MD, Broadus RR, Lu KH, Eifel PJ, Buchholz TA: Gene expression changes in cervical squamous cell carcinoma after initiation of chemoradiation and correlation with clinical outcome. Int J Radiat Oncol Biol Phys 2008, 71:226-236.

39. Jin $S$, Tong T, Fan W, Fan F, Antinore MJ, Zhu X, Mazzacurati L, Li X, Petrik KL, Rajasekaran B, Wu M, Zhan Q: GADD45-induced cell cycle G2-M arrest associates with altered subcellular distribution of cyclin B1 and is independent of p38 kinase activity. Oncogene 2002, 21:8696-8704.

40. Takekawa M, Saito H: A family of stress-inducible GADD45-like proteins mediate activation of the stress-responsive MTK1/MEKK4 MAPKKK. Cell 1998, 95:521-530.

41. Harkin DP, Bean JM, Miklos D, Song YH, Truong VB, Englert C, Christians FC, Ellisen LW, Maheswaran S, Oliner JD, Haber DA: Induction of GADD45 and JNK/SAPK-dependent apoptosis following inducible expression of BRCA1. Cell 1999, 97:575-586.

Pre-publication history

The pre-publication history for this paper can be accessed here:http://www. biomedcentral.com/1471-2407/10/71/prepub

doi:10.1186/1471-2407-10-71

Cite this article as: Qing et al: Microarray analysis of DNA damage repair gene expression profiles in cervical cancer cells radioresistant to ${ }^{252} \mathrm{Cf}$ neutron and X-rays. BMC Cancer 2010 10:71. 